\title{
Revised version
}

\section{Steric Effects and Aurophilic Interactions in Crystals of $\mathrm{Au}_{2}(\boldsymbol{\mu}-1,2-$ bis(diphenylphosphino)ethane) $X_{2}$ and $A_{2}(\mu-1,2-b i s(d i c y c l o h e x y l p h o s p h i n o) e t h a n e) X_{2}(X=$ Cl, Br, I).}

Daniel T. Walters, Kellie R. England, Kamran B. Ghiassi, Fikerete Z. Semma, Marilyn M. Olmstead, and Alan L. Balch*

Department of Chemistry, University of California, Davis, California 95616, U. S. A. E-mail, albalch@ucdavis.edu 


\begin{abstract}
Crystals in the isostructural series $\mathrm{Au}_{2}\left(\mu\right.$-dppe) $\mathrm{X}_{2}$ (dppe is 1,2bis(diphenylphosphino)ethane, $\mathrm{X}=\mathrm{Cl}, \mathrm{Br}, \mathrm{I}$ ) form centrosymmetric, dimeric structures with two short $\mathrm{Au} \cdots \mathrm{Au}$ contacts between the component molecules. We found no evidence for a second polymorph for any member of the $\mathrm{Au}_{2}\left(\mu\right.$-dppe) $\mathrm{X}_{2}$ series, although two polymorphs were observed previously for the related $\mathrm{Au}_{2}\left(\mathrm{Ph}_{2} \mathrm{As}\left(\mathrm{CH}_{2}\right)_{2} \mathrm{AsPh}_{2}\right) \mathrm{X}_{2}$ series. Crystals of $\mathrm{Au}_{2}(\mu-$ dcpe) $\mathrm{X}_{2}$ (where dcpe is 1,2-bis(dicyclohexylphosphino)ethane) show structures that differ appreciably from those of $\mathrm{Au}_{2}\left(\mu\right.$-dppe) $\mathrm{X}_{2}$. The bulky cyclohexyl substituents appear to be playing a major role eliminating the formation of polymeric or dimeric structures. $\operatorname{Au}_{2}(\mu-$ depe $) \mathrm{Cl}_{2}$ has a monomeric structure without aurophilic interactions. In contrast, $\mathrm{Au}_{2}(\mu-\mathrm{dcpe}) \mathrm{Br}_{2}$ and $\mathrm{Au}_{2}(\mu$-dcpe $) \mathrm{I}_{2}$ have similar structures with intramolecular aurophilic interactions. $\mathrm{Au}_{2}(\mu-$ dcpe) $\mathrm{I}_{2}$ displays a form of aggregation-induced emission. It displays a red-pink luminescence in crystalline form but is non-emissive in solution.
\end{abstract}




\section{Introduction}

The solid-state organization of molecules of gold(I) complexes frequently reflects the presence of aurophilic attractions between neighboring gold(I) centers. ${ }^{1}$ These aurophilic interactions arise from correlation and relativistic effects ${ }^{2,3}$ and result in attractive forces that are similar in energy to hydrogen bonds. ${ }^{4,5}$ Such aurophilic bonding results in close contacts between individual gold(I) centers with typical Au $\cdots$ Au distances that are less than $3.6 \AA .^{6,7,8,9}$

Diphosphine ligands of the type $\mathrm{R}_{2} \mathrm{P}\left(\mathrm{CH}_{2}\right)_{n} \mathrm{PR}_{2}$ can function effectively to connect two gold centers in a somewhat flexible fashion. For example, the short methylene connector in $\mathrm{Ph}_{2} \mathrm{P}\left(\mathrm{CH}_{2}\right) \mathrm{PPh}_{2}$ (dppm) facilitates the close approach of two metals and has been widely used to support metal-metal bonding and reactions that involve breaking or making metal-metal bonds. ${ }^{10,11,12}$ In contrast, when diphosphines with connectors consisting of three or more methylene units bridge two gold(I) centers, the gold ions are generally rather far apart. ${ }^{13,14,15,16,17}$ With $\mathrm{Ph}_{2} \mathrm{P}\left(\mathrm{CH}_{2}\right)_{2} \mathrm{PPh}_{2}$ (dppe) and related ligands that utilize two methylene connectors, there is considerable flexibility in positioning two metal centers. For example, the dimers $\operatorname{Au}_{2}(\mu-$ dppe $)_{2} \mathrm{Br}_{2}$ and $\mathrm{Au}_{2}(\mu \text {-dppe })_{2} \mathrm{I}_{2}$ consist of two, three-coordinate $\mathrm{P}_{2} \mathrm{AuX}$ units. ${ }^{18,19}$ Remarkably, the spacing between these three-coordinate, planar gold centers is variable and can range from $\sim 3.2 \AA$ to $\sim 3.8 \AA .{ }^{18,19}$ Thus, these molecules resemble molecular accordions. They are luminescent with their emission depending upon the Au»..Au separation. When that spacing is less than $3.5 \AA$, the dimers have a green emission, but when the spacing is greater than $3.5 \AA$, a red emission is observed. ${ }^{18,19}$ Our attempts to make the hypothetical molecular accordion "Au $2\left(\mu\right.$-dcpe) ${ }_{2} \mathrm{X}_{2}$ " (where dcpe is 1,2-bis(dicyclohexylphosphino)ethane and $\mathrm{X}$ can be $\mathrm{Cl}, \mathrm{Br}$, or I), in which the phenyl groups were replaced with cyclohexyl substituents that could not 
contribute to the luminescence, resulted exclusively in the formation of the two-coordinate complexes, $\operatorname{Au}_{2}\left(\mu\right.$-dcpe) $\mathrm{X}_{2}$.

Here, we present results on the related series of two-coordinate gold(I) complexes $\mathrm{Au}_{2}(\mu$-dppe $) \mathrm{X}_{2}$ and $\mathrm{Au}_{2}(\mu$-dcpe $) \mathrm{X}_{2}$. Molecules similar to $\mathrm{Au}_{2}(\mu$-dppe $) \mathrm{X}_{2}$ and $\mathrm{Au}_{2}(\mu$-dcpe $) \mathrm{X}_{2}$ can produce a variety of different structural types as shown in Scheme 1. The formation of polymeric structures (A) that involve aurophilic connecting these complexes is particularly common. ${ }^{20}$ For example, the molecules $\mathrm{Au}_{2}\left(\mu-\mathrm{Ph}_{2} \mathrm{P}\left(\mathrm{CH}_{2}\right)_{n} \mathrm{PPh}_{2}\right) \mathrm{I}_{2}$ with $n=4$ through 8 form polymers of this sort. ${ }^{21}$ The case of $\mathrm{Au}_{2}\left(\mu-\mathrm{Ph}_{2} \mathrm{P}\left(\mathrm{CH}_{2}\right)_{6} \mathrm{PPh}_{2}\right) \mathrm{I}_{2}$ is particularly interesting since the individual polymer strands in the crystal are interwoven to form discrete layers. ${ }^{22}$ As a result of this layered structure, preferential cleavage of crystals of $\mathrm{Au}_{2}\left(\mu-\mathrm{Ph}_{2} \mathrm{P}_{(}\left(\mathrm{CH}_{2}\right)_{6} \mathrm{PPh}_{2}\right) \mathrm{I}_{2}$ occurs along the crystallographic $a b$ plane, which is the plane containing the individual polymeric interwoven layers. As an alternative to polymer formation, molecules of the type $\mathrm{Au}_{2}(\mu-$ $\left.\mathrm{R}_{2} \mathrm{P}\left(\mathrm{CH}_{2}\right)_{n} \mathrm{PR}_{2}\right) \mathrm{X}_{2}$ can dimerize through the formation of two aurophilic interactions as shown in (B) in Scheme 1. This laboratory has recently shown that each of the related arsine analogs $\mathrm{Au}_{2}\left(\mu\right.$-dpae) $\mathrm{X}_{2}$ (dpae is 1,2-bis(diphenylarsino)ethane) forms two polymorphs, one with the polymeric structure (A) and the other with the dimeric structure (B). ${ }^{23}$ Molecules of the type $\mathrm{Au}_{2}\left(\mu-\mathrm{R}_{2} \mathrm{P}\left(\mathrm{CH}_{2}\right)_{n} \mathrm{PR}_{2}\right) \mathrm{X}_{2}$ can also from intramolecular aurophilic bonds as shown in $(\mathbf{C})$ of Scheme 1. Thus, $\mathrm{Au}_{2}\left(\mu\right.$-cis-dppee) $\mathrm{X}_{2}$ (dppee is cis-bis(diphenylphosphine)ethylene) adopts structure of type $(\mathbf{C})$ because the rigid backbone positions the two gold centers in close proximity. ${ }^{24,25}$ Finally, molecules of the type $\mathrm{Au}_{2}\left(\mu-\mathrm{R}_{2} \mathrm{P}\left(\mathrm{CH}_{2}\right)_{n} \mathrm{PR}_{2}\right) \mathrm{X}_{2}$ may have no aurophilic interactions at all as shown in (D) in Scheme 1. With four known structural motifs possible for the $\mathrm{Au}_{2}(\mu$-dppe $) \mathrm{X}_{2}$ and $\mathrm{Au}_{2}(\mu$-dcpe $) \mathrm{X}_{2}$ series, we identify here which motifs are actually found for these two series and explore their luminescent properties. 
Scheme 1. Binuclear Gold Complexes with Ligand Bridges and Varying Aurophilic Interactions.

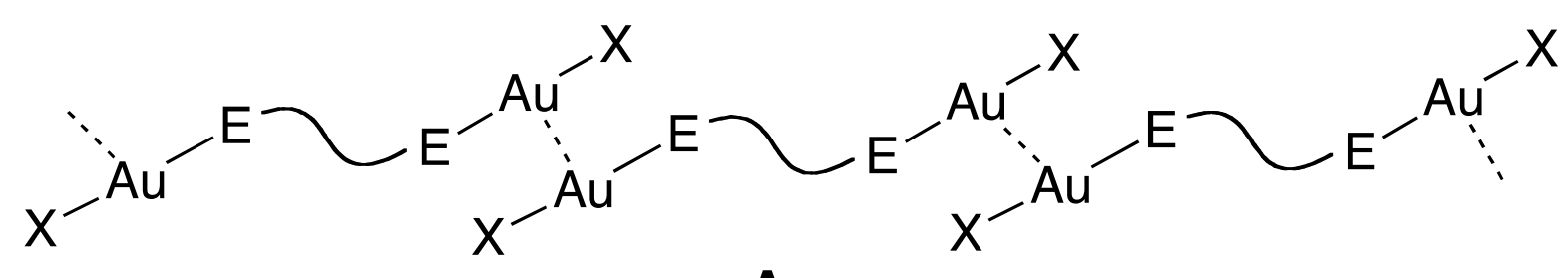

A
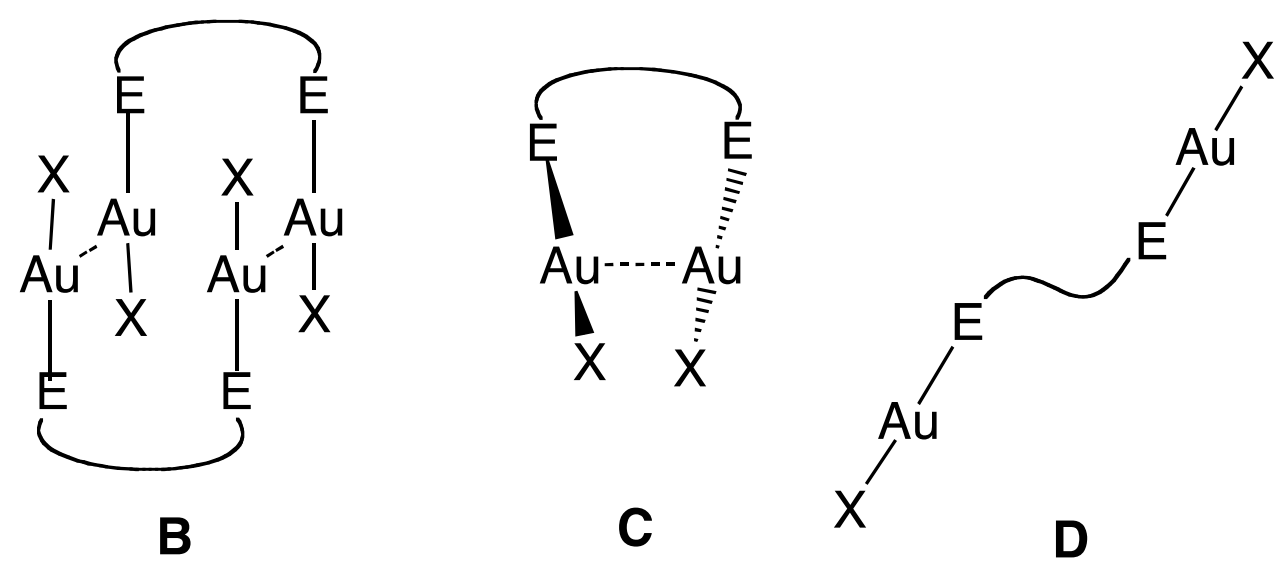

$\mathrm{E}=\mathrm{P}, \mathrm{As}$
$\mathrm{X}=\mathrm{Cl}, \mathrm{Br}, \mathrm{I}$ 


\section{Experimental Section}

2.1 Materials. Chloroauric acid, bromoauric acid, and gold(I) iodide were purchased from Strem Chemicals, Inc. The phosphine ligands were purchased from Sigma-Aldrich Co. LLC. 2 2'-thiodiethanol was purchased from Sigma-Aldrich. Solvents were obtained commercially. All materials were used as received unless otherwise specified. $\mathrm{Au}_{2}\left(\mu\right.$-dppe) $\mathrm{Cl}_{2}$ was prepared according to literature methods. ${ }^{26,27}$

2.2 Preparation of $\mathbf{A u}_{2}(\boldsymbol{\mu}$-dppe)Br2. A $200 \mathrm{mg}$ (0.386 mmol) portion of bromoauric acid was added to $10 \mathrm{~mL}$ methanol at room temperature. While stirring, $0.50 \mathrm{~mL}$ of $2,2^{\prime}$-thiodiethanol (4.8 mmol) was added dropwise. During 10 minutes of stirring, the solution faded from red-orange to gold. A $150 \mathrm{mg}(0.376 \mathrm{mmol})$ portion of dppe was dissolved in methanol and the solutions combined. The resulting solution was stirred until the solution color faded to pale gold. The solution was heated to $50{ }^{\circ} \mathrm{C}$ for 30 minutes. Upon addition of $50 \mathrm{mg}(0.62 \mathrm{mmol})$ of sodium thiocyanate, the color of the solution faded and a white suspension formed. Evaporation of the solvent yielded a white powder. The crude solid (168 mg 83\%) was collected by filtration and washed with three $10 \mathrm{~mL}$ aliquots of diethyl ether. Colorless crystals formed via slow diffusion of hexane or diethyl ether into a dichloromethane solution of the complex. IR spectrum: $3328 \mathrm{w}$, 3050w, 2937w, 2921w, 2871w, 2172w, 2128w, 2072w, 1959w, 1738m, 1578w, 1476m, 1429s, $1407 \mathrm{~m}, 1376 \mathrm{~m}, 1333 \mathrm{w}, 1284 \mathrm{w}, 1221 \mathrm{w}, 1164 \mathrm{~m}, 1100 \mathrm{~s}, 1042 \mathrm{~s}, 999 \mathrm{~s}, 944 \mathrm{w}, 883 \mathrm{w}, 848 \mathrm{w}, 792 \mathrm{w}$, 726s, 684s, 518s, 470s, 398w. ${ }^{31} \mathrm{P}\left\{{ }^{1} \mathrm{H}\right\}$ NMR (chloroform-d, $298 \mathrm{~K}$ ): singlet at $35.1 \mathrm{ppm}$. Melting point: $245-250^{\circ} \mathrm{C}$ (decomposition) 
2.3 Preparation of $\mathbf{A u}_{2}\left(\boldsymbol{\mu}\right.$-dppe) $\mathbf{I}_{2}$. AuI $(100 \mathrm{mg}, 0.309 \mathrm{mmol})$ was suspended in $30 \mathrm{~mL}$ of acetone. Solid dppe (185 mg, $0.463 \mathrm{mmol})$ was added while stirring. After stirring for three hours, the solution was filtered and the solvent removed in a vacuum to yield "Au(dppe)I"19 (180 mg). A $100 \mathrm{mg}$ portion of "Au(dppe)I" $(0.0692 \mathrm{mmol})$ was dissolved in $25 \mathrm{~mL}$ dichloromethane. While stirring, $22 \mathrm{mg}$ of $\mathrm{I}_{2}(0.087 \mathrm{mmol})$ dissolved in a minimal amount of dichloromethane was added. Upon addition of $\mathrm{I}_{2}$, the suspension turned gold, which faded to colorless after an hour. The suspension was stirred for 3 hours and the solvent removed via evaporation. The crude white powder was washed with three aliquots of diethyl ether. The crude yield was $112 \mathrm{mg}$ (77.2 \%). Crystals were formed by slow diffusion of diethyl ether into a solution of the product in dichloromethane. IR spectrum: 3053w, 1588w, 1482w, 1433m, 1406w, 1316w, 1310w, 1261w, 1164w, 1140w, 1121m, 1095w, 1067w, 989w, 995w, 920w, 876w, 846w, 765w, 726s, 689s, 616w, 530m, 504s, 421w. ${ }^{31} \mathrm{P}\left\{{ }^{1} \mathrm{H}\right\}$ NMR (chloroform- $d, 298 \mathrm{~K}$ ): singlet at $32.5 \mathrm{ppm} .{ }^{1} \mathrm{H}-$ NMR (chloroform- $d, 298 \mathrm{~K}$ ): 2.01 (br) methylenes, 7.45 (t) $m-\mathrm{H}, 7.52$ (t) $p-\mathrm{H}, 7.70$ (q) $o-\mathrm{H}$. Melting point: $154-156^{\circ} \mathrm{C}$. Mass spectrum positive mode: m/z 918.795 [dppe(AuI)Au] ${ }^{+}$.

2.4 Preparation of $\mathbf{A u}_{2}(\mu$-dcpe $) \mathbf{C l}_{2}$. A $217 \mathrm{mg}(0.639 \mathrm{mmol})$ portion of chloroauric acid was dissolved in a mixture of $5 \mathrm{~mL}$ deionized water and $7.5 \mathrm{~mL}$ of methanol and cooled to $0^{\circ} \mathrm{C}$ in a bath of acetone and ice. Separately, $163 \mu \mathrm{L}(1.63 \mathrm{mmol})$ of 2,2'-thiodiethanol was dissolved in $2.5 \mathrm{~mL}$ of methanol and then slowly added to the chloroauric acid solution. After 15 minutes of stirring, the solution became colorless. A $139 \mathrm{mg}(0.330 \mathrm{mmol})$ portion of dcpe was dissolved in a mixture of $5 \mathrm{~mL}$ methanol and $5 \mathrm{~mL}$ of acetonitrile. This mixture was added slowly to the chloroauric acid solution. Upon addition, a precipitate formed rapidly and redissolved while stirring. After 30 minutes of stirring, persistent precipitation was observed and $50 \mathrm{~mL}$ of dry 
methanol was added to aid in completion of precipitation. The crude solid was collected by filtration and washed with three $10 \mathrm{~mL}$ aliquots of methanol. Additional precipitate was observed in the supernatant upon warming to room temperature. This precipitate was also collected by filtration, washed with methanol, and combined with the other precipitate. The yield of crude product was $182 \mathrm{mg}(94.5 \%)$. The product was dissolved in $8 \mathrm{~mL}$ of dichloromethane and recrystallized by slow diffusion of diethyl ether, methanol, and toluene in separate containers. Each combination produced identical crystals suitable for X-ray diffraction. Infrared spectrum: 2922s, 2848s, 1440s, 1334w, 1296w, 1267w, 1188m, 1114m, 1047w, 1002m, 889m, 852m, 820m, 750s, 704m, 674m, 524s, 484s, 441w, 402m. ${ }^{31} \mathrm{P}\left\{{ }^{1} \mathrm{H}\right\}$ NMR (chloroform- $d$, $298 \mathrm{~K}$ ): singlet at $50.0 \mathrm{ppm} .{ }^{1} \mathrm{H}-\mathrm{NMR}$ (chloroform- $d, 298 \mathrm{~K}$ ): 1.20-1.45 (m), 1.72-2.05 (m). Melting Point: $225^{\circ}$ (decomposition into red-pink solid). Mass spectrum positive mode: $\mathrm{m} / \mathrm{z}$ $851.084[\mathrm{dcpe}(\mathrm{AuCl}) \mathrm{Au})]^{+}$.

2.5 Preparation of $\mathbf{A u}_{2}(\boldsymbol{\mu}$-dcpe $) \mathrm{Br}_{2}$. A $288 \mathrm{mg}(0.557 \mathrm{mmol})$ portion of bromoauric acid was dissolved in a mixture of $7.5 \mathrm{~mL}$ methanol and $5 \mathrm{~mL}$ deionized water cooled to $0^{\circ} \mathrm{C}$ in a bath of acetone and ice, resulting in a red solution. Separately, $173 \mu \mathrm{L}$ of $(1.67 \mathrm{mmol}) 2,2$ 'thiodiethanol was dissolved in $2.5 \mathrm{~mL}$ of methanol and added drop wise over 10 minutes to the chilled bromoauric acid solution. The color of the solution gradually faded to produce a colorless mixture. A $118 \mathrm{mg}(0.281 \mathrm{mmol})$ portion of dcpe was dissolved in a mixture of $5 \mathrm{~mL}$ methanol and $5 \mathrm{~mL}$ acetonitrile. The two solutions were mixed and produced immediate precipitation of the crude product. The solution was warmed to room temperature, then $50 \mathrm{~mL}$ of methanol was added to complete the precipitation. The colorless solid was collected by filtration and washed with three $10 \mathrm{~mL}$ portions of methanol. The total yield of crude product 
was $149 \mathrm{mg}(55 \%)$. The product was dissolved in $8 \mathrm{~mL}$ of dichloromethane and recrystallized by slow diffusion of diethyl ether, ethanol, and toluene in separate containers. Each combination produced identical crystals suitable for X-ray diffraction. Infrared spectrum: 2921s, 2849s, $1442 \mathrm{~s}, 1413 \mathrm{w}, 1327 \mathrm{w}, 1296 \mathrm{w}, 1270 \mathrm{~m}, 1201 \mathrm{w}, 1187 \mathrm{~s}, 1171 \mathrm{~m}, 1110 \mathrm{~m}, 1051 \mathrm{w}, 1004 \mathrm{~m}, 913 \mathrm{w}$, 891m, 852s, 822m, 752s, 706m, 676m, 514s, 513s, 484s, 440m, 402m. ${ }^{31} \mathrm{P}\left\{{ }^{1} \mathrm{H}\right\} \quad \mathrm{NMR}$ (chloroform- $d, 298 \mathrm{~K}$ ): singlet at 52.1 ppm. ${ }^{1} \mathrm{H}-\mathrm{NMR}$ (chloroform- $d, 298 \mathrm{~K}$ ): 1.20-1.48 (m), 1.70-2.06 (m). Melting Point: $235^{\circ}$ (decomposition). Mass spectrum positive mode: $\mathrm{m} / \mathrm{z}$ $895.060[\mathrm{dcpe}(\mathrm{AuBr}) \mathrm{Au})]^{+}$.

2.6 Preparation of $\mathbf{A u}_{2}(\boldsymbol{\mu}$-dcpe $) \mathbf{I}_{2}$. A $58 \mathrm{mg}(0.18 \mathrm{mmol})$ portion of gold(I) iodide was placed in $6 \mathrm{~mL}$ of dichloromethane and sonicated for 10 minutes to produce a yellow suspension. Excess dcpe (114 mg, $0.270 \mathrm{mmol}$ ) was added directly, which resulted in the formation of a clear, colorless solution. This solution was covered and stirred vigorously for two hours, then uncovered and allowed to evaporate overnight. The crude solid product was obtained in quantitative yield. Upon drying, the solid product was dissolved in dichloromethane and recrystallized by slow diffusion of diethyl ether, methanol, ethanol, propanol, and toluene in separate containers. Each combination produced identical crystals suitable for X-ray diffraction. Infrared spectrum: 2922s, 2848s, 1443s, 1329w, 1267w, 1187m, 1111w, 1050w, 1004m, 888m, 852m, 818m, 753s, 707m, 676m, 525s, 485s, 440w, 407m. ${ }^{31} \mathrm{P}\left\{{ }^{1} \mathrm{H}\right\}$ NMR (chloroform- $d, 298$ K): singlet at 54.9 ppm. ${ }^{1} \mathrm{H}-\mathrm{NMR}$ (chloroform- $d, 298 \mathrm{~K}$ ): 1.20-2.14 (m). Melting Point: 251 $258^{\circ} \mathrm{C}$ (decomposition). Mass spectrum positive mode: m/z 943.3719 [dcpe(AuI)Au) $]^{+}$. 
2.7 X-ray Crystallography and Data Collection. Crystals of $\mathrm{Au}_{2}\left(\mu\right.$-dcpe) $\mathrm{Br}_{2}, \mathrm{Au}_{2}\left(\mu\right.$-dcpe) $\mathrm{Cl}_{2}$, and $\mathrm{Au}_{2}(\mu$-dppe $) \mathrm{Cl}_{2}$ were mounted in the $100 \mathrm{~K}$ nitrogen cold stream provided by an Oxford Cryostream low-temperature apparatus on the goniometer head of a Bruker D8 diffractometer equipped with a Photon $100 \mathrm{CMOS}$ detector. Data were collected using synchrotron radiation $(\lambda$ $=0.6888 \AA$ ) at Beamline 11.3.1 at the Advanced Light Source, Lawrence Berkeley National Laboratory. Crystals of $\mathrm{Au}_{2}\left(\mu\right.$-dppe) $\mathrm{Br}_{2}$, and $\mathrm{Au}_{2}\left(\mu\right.$-dppe) $\mathrm{I}_{2}, \mathrm{Au}_{2}\left(\mu\right.$-dcpe) $\mathrm{I}_{2}$ were mounted in a $90 \mathrm{~K}$ cold stream provided by a Cryo Industries low-temperature apparatus on the goniometer head of a Bruker D8 Apex II diffractometer employing $\operatorname{Mo~}_{\alpha}(\lambda=0.71073 \AA)$ radiation and a CCD detector. All data sets were reduced using SAINT ${ }^{28}$ and a multiscan absorption correction was applied using SADABS. ${ }^{29}$ Structure solution and refinement were executed using direct or dual methods ${ }^{30}$ and refined using all data (based on $F_{2}$ ) using SHELXL-2014. ${ }^{31}$ Additional refinement details can be found in the crystallographic information files (CIFs).

2.8 Physical Measurements. Infrared spectra were recorded on neat powders on a Bruker ALPHA FT-IR spectrometer. Fluorescence excitation and emission spectra were recorded on a Perkin-Elmer LS50B luminescence spectrophotometer. NMR data were collected on a Bruker Avance DRX $500 \mathrm{MHz}$ spectrometer. ${ }^{31} \mathrm{P}\left\{{ }^{1} \mathrm{H}\right\}$ chemical shifts are referenced to external phosphoric acid.

\section{Results}

\subsection{Synthesis and Crystal Growth}

Colorless $\mathrm{Au}_{2}(\mu$-dppe $) \mathrm{Cl}_{2}$ was prepared in a similar fashion as reported earlier. ${ }^{26,27}$ Crystals of $\mathrm{Au}_{2}\left(\mu\right.$-dppe) $\mathrm{Br}_{2}$ were obtained by reduction of bromoauric acid with $2,2^{\prime}-$ thiodiethanol followed by the addition of dppe. This produced a golden solution that was treated 
with sodium thiocyanate, which appears to act as a second reducing agent, since its addition caused the solution to fade to colorless. Evaporation of the solvent yielded a white powder in $83 \%$ yield. Colorless crystals of $\mathrm{Au}_{2}\left(\mu\right.$-dppe) $\mathrm{Br}_{2}$ were formed via slow diffusion of hexane or diethyl ether into a dichloromethane solution of the complex. Treatment of solid gold(I) iodide with an acetone solution of dppe produced a colorless solution that upon evaporation yielded "Au(dppe)I" as a white powder. ${ }^{19} \quad$ As previously reported, recrystallization of this white powder produced $\mathrm{Au}_{2}(\mu \text {-dppe })_{2} \mathrm{I}_{2}$ with two, three-coordinate gold centers and a variable spacing between these gold centers and $\mathrm{Au}_{2}(\mu \text {-dppe })_{2}(\mu-\mathrm{I})_{2}$ with two, four-coordinate gold centers. ${ }^{19}$ Attempts to oxidize "Au(dppe)I" with diiodine produced only colorless $\mathrm{Au}_{2}\left(\mu\right.$-dppe) $\mathrm{I}_{2}$ in $77 \%$ yield.

Efforts to obtain the target molecule "Au2( $\mu$-dcpe $)_{2} \mathrm{X}_{2}$ ", were unsuccessful although we did examine a variety of reaction conditions and reaction stoichiometries, but we were able to prepare and characterize the two-coordinate complexes, $\operatorname{Au}_{2}(\mu$-dcpe $) X_{2}$. Colorless crystals of $\mathrm{Au}_{2}(\mu$-dcpe $) \mathrm{Cl}_{2}$ and $\mathrm{Au}_{2}\left(\mu\right.$-dcpe) $\mathrm{Br}_{2}$ were obtained in 94 or $55 \%$ yield respectively by reduction of either $\mathrm{HAuCl}_{4}$ or $\mathrm{HAuBr}_{4}$ with 2,2'-thiodiethanol followed by the addition of depe. Treatment of a yellow suspension of AuI in dichloromethane with dcpe yielded colorless $\mathrm{Au}_{2}(\mu-$ dcpe) $I_{2}$ in essentially quantitative yield.

Infrared and ${ }^{31} \mathrm{P}\left\{{ }^{1} \mathrm{H}\right\}$ NMR spectral data for all of these complexes are given in the experimental section.

\subsection{The Molecular and Supramolecular Structures of the Isostructural Series: $\mathbf{A u}_{2}(\mu-$ dppe)Cl $\mathbf{C l}_{2}, \mathrm{Au}_{2}(\mu-\mathrm{dppe}) \mathrm{Br}_{2}$, and $\mathrm{Au}_{2}\left(\mu\right.$-dppe) $\mathbf{I}_{2}$}

Crystallographic data for this series of compounds are presented in Table1. Selected bond distances and angles are given in Table 2. The molecular structure of $\operatorname{Au}_{2}\left(\mu\right.$-dppe) $\mathrm{I}_{2}$, which 
is representative of the series, is shown in Figure 1 and is akin to $\mathbf{D}$ of Scheme 1. The Newman projection angles, $\mathrm{X}-\mathrm{Au} \cdots \mathrm{Au}-\mathrm{X}$, and part $(\mathbf{B})$ of Figure 1 show that the monomer is twisted into a

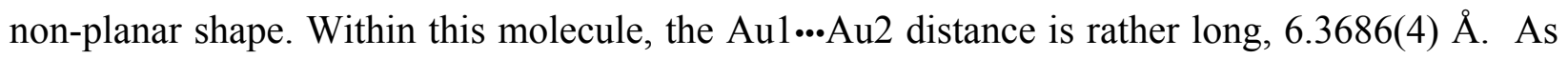
shown in Figure 2, in the solid state, two molecules of $\mathrm{Au}_{2}\left(\mu\right.$-dppe) $\mathrm{I}_{2}$ self associate to form a centrosymmetric dimer through intermolecular aurophilic interactions, as in B of Scheme 1. The Au1 ...Au2A distance in the dimer is 3.1552(2) $\AA$. Similar molecular structures and selfassociation are seen in $\mathrm{Au}(\mu$-dppe $) \mathrm{Br}_{2}$ and for $\mathrm{Au}(\mu$-dppe $) \mathrm{Cl}_{2}$. The structure of $\mathrm{Au}_{2}(\mu$-dppe $) \mathrm{Cl}_{2}$ is entirely consistent with previous reports, ${ }^{27,28}$ but we include our low temperature structure for direct comparison with the other complexes reported here. Additionally, $\mathrm{Au}_{2}(\mu-\mathrm{dppe}) \mathrm{Cl}_{2}$, $\mathrm{Au}_{2}\left(\mu\right.$-dppe) $\mathrm{Br}_{2}$, and $\mathrm{Au}_{2}(\mu$-dppe $) \mathrm{I}_{2}$ are isostructural with the $\alpha$-polymorphs of $\mathrm{Au}_{2}(\mu$-dpae $) \mathrm{X}_{2}$ $(\mathrm{X}=\mathrm{Cl}, \mathrm{Br}, \mathrm{I})$. However, despite repeated efforts, we were not able to detect any other polymorphic forms of $\mathrm{Au}_{2}\left(\mu\right.$-dppe)Cl $\mathrm{Cl}_{2}, \mathrm{Au}_{2}\left(\mu\right.$-dppe)Br, or $\mathrm{Au}_{2}(\mu$-dppe $) \mathrm{I}_{2}$.

\subsection{The Structure of $\mathrm{Au}_{2}(\mu-d c p e) \mathrm{Cl}_{2}$.}

Crystallographic data for the $\mathrm{Au}_{2}(\mu$-dcpe $) \mathrm{Cl}_{2}(\mathrm{X}=\mathrm{Cl}, \mathrm{Br}$, and I) series of compounds are given in Table 3, while selected bond distances and angles are given in Table 4. Figure 3 shows the molecular structure of $\mathrm{Au}_{2}(\mu-\mathrm{dcpe}) \mathrm{Cl}_{2}$. Within the molecule, the gold ions are separated by

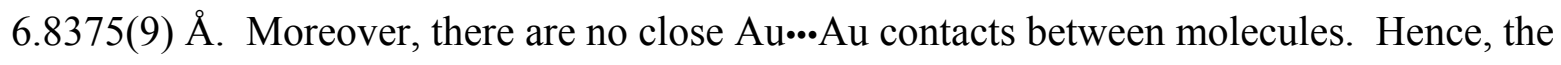
monomeric structure of $\mathrm{Au}_{2}(\mu$-dcpe $) \mathrm{Cl}_{2}$ contrasts with that of the series $\mathrm{Au}_{2}(\mu$-dppe $) \mathrm{X}_{2}$ which self-associate through two intermolecular Au..A Au interactions. In the absence of any aurophilic interactions, the $\mathrm{P}-\mathrm{Au}-\mathrm{Cl}$ angle, $177.07(3)^{\circ}$, in $\mathrm{Au}_{2}(\mu$-dcpe $) \mathrm{Cl}_{2}$ is more nearly linear than the corresponding angles seen in any of the other complexes reported here. 


\subsection{The Structures of $\mathrm{Au}_{2}(\mu-\mathrm{dcpe}) \mathrm{Br}_{2}$ and $\mathrm{Au}_{2}(\mu-\mathrm{dcpe}) \mathrm{I}_{2}$.}

As the crystallographic data in Table 3 show, these two compounds are isostructural. Drawings of the two similar molecules are shown in Figure 4. These two complexes have a twisted shape in which the two gold centers are drawn together by aurophilic interactions as in $\mathbf{C}$ of Scheme 1. The Au1 ...Au2 distances in these monomers (Au2( $\mu$-dcpe)Br2, 3.1511(7) $\AA ; \mathrm{Au}_{2}(\mu-$ dcpe)I2, 3.1087(4) $\AA$ ) are significantly shorter than the corresponding intermolecular distances seen in the $\mathrm{Au}_{2}(\mu-\mathrm{dppe}) \mathrm{Cl}_{2}(\mathrm{X}=\mathrm{Cl}, \mathrm{Br}$, and I) series. The $\mathrm{P}-\mathrm{Au}-\mathrm{X}$ angles in these two monomers are slightly bent inward in a fashion that reflects the neighboring attractive aurophilic interactions.

\subsection{Luminescence of Crystalline $\mathrm{Au}_{2}(\mu-\mathrm{dcpe}) \mathrm{I}_{2}$.}

Samples of $\mathrm{Au}_{2}(\mu$-dppe $) \mathrm{X}_{2}$ and $\mathrm{Au}_{2}(\mu$-dcpe $) \mathrm{X}_{2}(\mathrm{X}=\mathrm{Cl}, \mathrm{Br}$, and I) both in solution and in the solid state have been examined for luminescence. As seen in Figures 5 and 6, crystalline $\operatorname{Au}_{2}(\mu-d c p e) I_{2}$ displays a pink luminescence. None of the other five compounds discussed here show any luminescence in the crystalline state or in solution. As Figure 5 shows, a solution of $\operatorname{Au}_{2}(\mu-d c p e) I_{2}$ is not luminescent, but the material becomes luminescent upon crystallization. The emission spectrum shows two peaks, which may come from vibrational fine structure or the fact that there are two non-equivalent gold centers in the crystal structure. We have ruled out the possibility that two polymorphs are present by examining a number of crystals by both X-ray diffraction and emission spectroscopy. All crystals show the same emission features with identical intensity ratios."

\section{Discussion}


Crystals in the series $\mathrm{Au}_{2}(\mu$-dppe $) \mathrm{X}_{2}(\mathrm{X}=\mathrm{Cl}, \mathrm{Br}, \mathrm{I})$ are isostructural and isostructural with the $\alpha$-polymorphs of $\mathrm{Au}_{2}\left(\mu\right.$-dpae) $\mathrm{X}_{2}$. They form centrosymmetric, dimeric structures of type (B) in Scheme 1. Although a second, unique polymorph was identified for each member of the $\mathrm{Au}_{2}\left(\mu\right.$-dpae) $\mathrm{X}_{2}$ series that had the polymeric structure (A) in Scheme 1, we found no evidence for a second polymorph for any member of the $\mathrm{Au}_{2}(\mu$-dppe $) \mathrm{X}_{2}(\mathrm{X}=\mathrm{Cl}, \mathrm{Br}, \mathrm{I})$ series.

Crystals of $\mathrm{Au}_{2}(\mu$-dcpe $) \mathrm{X}_{2}$ show structures that differ appreciably from those of $\mathrm{Au}_{2}(\mu-$ dppe) $\mathrm{X}_{2}$. The bulky cyclohexyl substituents appear to be playing a major role eliminating the formation of polymeric or dimeric structures. $\mathrm{Au}_{2}(\mu-\mathrm{dcpe}) \mathrm{Cl}_{2}$ has a rather uncommon, monomeric structure with no aurophilic interactions. In this situation, the cyclohexyl groups are position to avoid any intramolecular contact. In contrast, $\mathrm{Au}_{2}(\mu-\mathrm{dcpe}) \mathrm{Br}_{2}$ and $\mathrm{Au}_{2}(\mu-\mathrm{dcpe}) \mathrm{I}_{2}$ have similar structures with intramolecular aurophilic interactions. As seen in Figure 4, the bulky cyclohexyl substituents in these two complexes again are situated so that contact between any of them is minimized. The intramolecular $\mathrm{Au} \cdots \mathrm{Au}$ distances in $\mathrm{Au}_{2}(\mu$-depe $) \mathrm{Br}_{2}$ and $\mathrm{Au}_{2}(\mu-$ dcpe) $I_{2}(3.1511(7)$ and 3.1087(4) $\AA$, respectively) are similar to the intermolecular $\mathrm{Au} \cdots \mathrm{Au}$ distances in $\mathrm{Au}_{2}\left(\mu\right.$-dppe) $\mathrm{Br}_{2}$ and $\mathrm{Au}_{2}\left(\mu\right.$-dppe) $\mathrm{I}_{2}$ (3.1703(4) and 3.1552(2) $\AA$, respectively). In $\mathrm{Au}_{2}\left(\mu\right.$-dppm) $\mathrm{Cl}_{2}$, which also has an intramolecular aurophilic interaction, the $\mathrm{Au} \cdots \mathrm{Au}$ distance is considerably longer $(3.341 \AA) .{ }^{32}$ However, $\operatorname{Au}_{2}(\mu$-cis-dppee)I2, where dppee is cis-di(phenylphosphine)ethylene, has a structure of type (C) with the two gold centers positioned closer together with a $\mathrm{Au} \cdots \mathrm{Au}$ distance of $2.9526(5) \AA .^{25}$ The differences between the structure of $\mathrm{Au}_{2}(\mu$-dcpe $) \mathrm{X}_{2}$ and those of $\mathrm{Au}_{2}(\mu$-dcpe $) \mathrm{Br}_{2}$ and $\mathrm{Au}_{2}(\mu$-dcpe $) \mathrm{I}_{2}$ are likely to result from subtle differences in packing efficiency that are tied to the differences in the lengths of the Au-X bonds, the sizes of the halides, and the strength of the aurophilic interactions. 
Of the compounds reported here, only crystalline $\mathrm{Au}_{2}(\mu-d c p e) \mathrm{I}_{2}$ is luminescent at room temperature. Given the large Stokes' shift involved, the emission appears to be phosphorescence. Solution of $\mathrm{Au}_{2}(\mu$-dcpe $) I_{2}$ are non-luminescent. Consequently, $\mathrm{Au}_{2}(\mu$-dcpe $) \mathrm{I}_{2}$ displays aggregation induced emission. ${ }^{33}$ Many luminescent molecules show diminished luminescence intensity, if any, when condensed into solid form, a phenomenon known as aggregation caused quenching. Here, we have the opposite situation: only upon crystallization does $\mathrm{Au}_{2}(\mu-\mathrm{dcpe}) \mathrm{I}_{2}$ emit. A number of gold complexes undergo self-association upon crystallization and become emissive with the emission linked to the formation of aurophilic interactions between individual gold(I) complexes. ${ }^{34,35,36}$ However, in the present case no self-association occurs. Rather, we suggest that the $\mathrm{Au}_{2}(\mu$-dcpe $) \mathrm{I}_{2}$ molecule exists in solution in a freely rotating form that is free from aurophilic interactions, but upon crystallization the molecule becomes locked in an arrangement that favors interaction between the two gold centers. In this context, the nonemissive nature of crystalline $\mathrm{Au}_{2}(\mu-\mathrm{dcpe}) \mathrm{Br}_{2}$ is some what surprising, until one realizes that both polymorphs of $\mathrm{Au}_{2}(\mu-d p a e) \mathrm{Cl}_{2}$ and $\mathrm{Au}_{2}(\mu-d p a e) \mathrm{I}_{2}$ are luminescent, but neither polymorph of $\mathrm{Au}_{2}(\mu$-dpae $) \mathrm{Br}_{2}$ is emissive. ${ }^{23}$

Acknowledgements. We thank the Petroleum Research Fund (Grant 37056-AC) and the National Science Foundation for financial support (Grant CHE-1305125 to A.L.B. and M.M.O. for support. We thank the Advanced Light Source, supported by the Director, Office of Science, Office of Basic Energy Sciences, of the U.S. Department of Energy under Contract DE-AC0205CH11231, for beam time and a fellowship to K.B.G. 


\section{References}

[1] A.L. Balch, Struct. Bond. 123 (2007) 1.

[2] P. Pyykkö, Chem. Soc. Rev. 37 (2008) 1967.

[3] P. Pyykkö, Inorg. Chim. Acta 358 (2005) 4113.

[4] H. Schmidbaur, W. Graf, G. Müller, Angew. Chem., Int. Ed. 27 (1988) 417.

[5] D.E. Harwell, M.D. Mortimer, C.B. Knobler, F.A.L. Anet, M.F. Hawthorne, J. Am. Chem. Soc. 118 (1996) 2679.

[6] S.S. Pathaneni, G.R. Desiraju, J. Chem. Soc. Dalton Trans. (1993) 319.

[7] K.A. Anderson, A.E. Goeta, J.W. Steed, Inorg. Chem. 46 (2007) 6444.

[8] H. Schmidbaur, A. Schier, Chem. Soc. Rev. 37 (2008) 1931.

[9] H. Schmidbaur, A. Schier, Chem. Soc. Rev. 41 (2012) 370.

[10] B. Chaudret, B. Delavaux, R. Poilblanc, Coord. Chem. Rev. 86 (1988) 191.

[11] R.J. Puddephatt, Chem. Soc. Rev. 12 (1983) 99.

[12] M.M. Olmstead, H. Hope, L.S. Benner, A.L. Balch, J. Am. Chem. Soc. 99 (1977) 5502.

[13] A.L. Balch, B. Tulyathan. Inorg. Chem. 16 (1977) 2840.

[14] P.M. Van Calcar, M.M. Olmstead, A.L. Balch. Inorg. Chem. 36 (1997) 5231.

[15] S. Onaka, M. Yaguchi, R. Yamauchi, T. Ozeki, M. Ito, T. Sunahara, Y. Sugiura, M. Shiotsuka, K. Nunokawa, M.Horibe, K. Okazaki, A. Iida, H. Chiba, K. Inoue, H. Imai, K. Sako, J. Organometal. Chem. 690 (2005) 57.

[16] S.H. Lim, J.C. Schmitt, J. Shearer, J. Jia, M.M. Olmstead, J.C. Fettinger, A.L. Balch, Inorg. Chem. 52 (2013) 823.

[17] M. Streitberger, A. Schmied, E. Hey-Hawkins, Inorg. Chem. 53 (2014) 6794.

[18] S.H. Lim, M.M. Olmstead, A.L. Balch, J. Am. Chem. Soc. 133 (2011) 10229. 
[19] S. H. Lim, M.M. Olmstead, A.L. Balch, Chem. Science 4 (2013) 311.

[20] R.J. Puddephatt, Coord. Chem. Rev. 216-217 (2001) 313.

[21] P.M. Van Calcar, M.M. Olmstead, A.L. Balch, Inorg. Chem. 36 (1997) 5231.

[22] P.M. Van Calcar, M.M. Olmstead, A.L. Balch, J. Chem. Soc., Chem. Commun. (1995) 1773.

[23] S.H. Lim, M.M. Olmstead, J.C. Fettinger, A.L. Balch, Inorg. Chem. 51 (2012) 1925.

[24] P.G. Jones, Acta Crystallogr., Sect. B. 36 (1980) 2775.

[25] J.B. Foley, S.E. Gay, M.J. Vela, B.M. Foxman, A.E. Bruce, M.R.M. Bruce, Eu. J. Inorg. Chem. 31 (2007) 4946.

[26] P.A. Bates, J.M. Waters, Inorg. Chim. Acta. 98 (1985) 125.

[27] D.S. Eggleston, D.F. Chodosh, G.R. Girard, D.T. Hill, Inorg. Chim. Acta. 108 (1985) 221.

[28] Bruker AXS Inc., Madison,Wisconsin, USA (2015).

[29] G. M. Sheldrick, University of Göttingen, Germany (2015).

[30] G. M. Sheldrick, Acta Crystallogr., Sect A. 64 (2008) 112; G. M. Sheldrick, Acta Crystallogr. Sect. A. 71 (2015) 3.

[31] G. M. Sheldrick, Acta Crystallogr. Sect. C. 71 (2015) 3.

[32] H. Schmidbaur, A. Wohlleben, F. Wagner, O. Orama, G. Huttner, Chem. Ber. 110, (1977) 1748.

[33] J. Mei, N. L. C. Leung, R. T.K Kwok, J.W.Y. Lam, BZ Tang, Chem. Rev. 115(2015) 11718.

[34] R.L. White-Morris, M.M. Olmstead, F. Jiang, D.S. Tinti, A.L. Balch, J. Am. Chem. Soc. 124 (2002) 2327.

[35] R.L. White-Morris, M.M. Olmstead, A.L. Balch, J. Am. Chem. Soc. 125 (2003) 1033. 
[36] M.A. Malwitz, S.H. Lim, R.L. White-Morris, D.M. Pham, M.M. Olmstead, A.L. Balch, J. Am. Chem. Soc. 134 (2012) 10885. 


\section{Table 1.}

Crystal Data and Structure Refinement for $\mathrm{Au}_{2}\left(\mu\right.$-dppe) $\mathrm{X}_{2}$

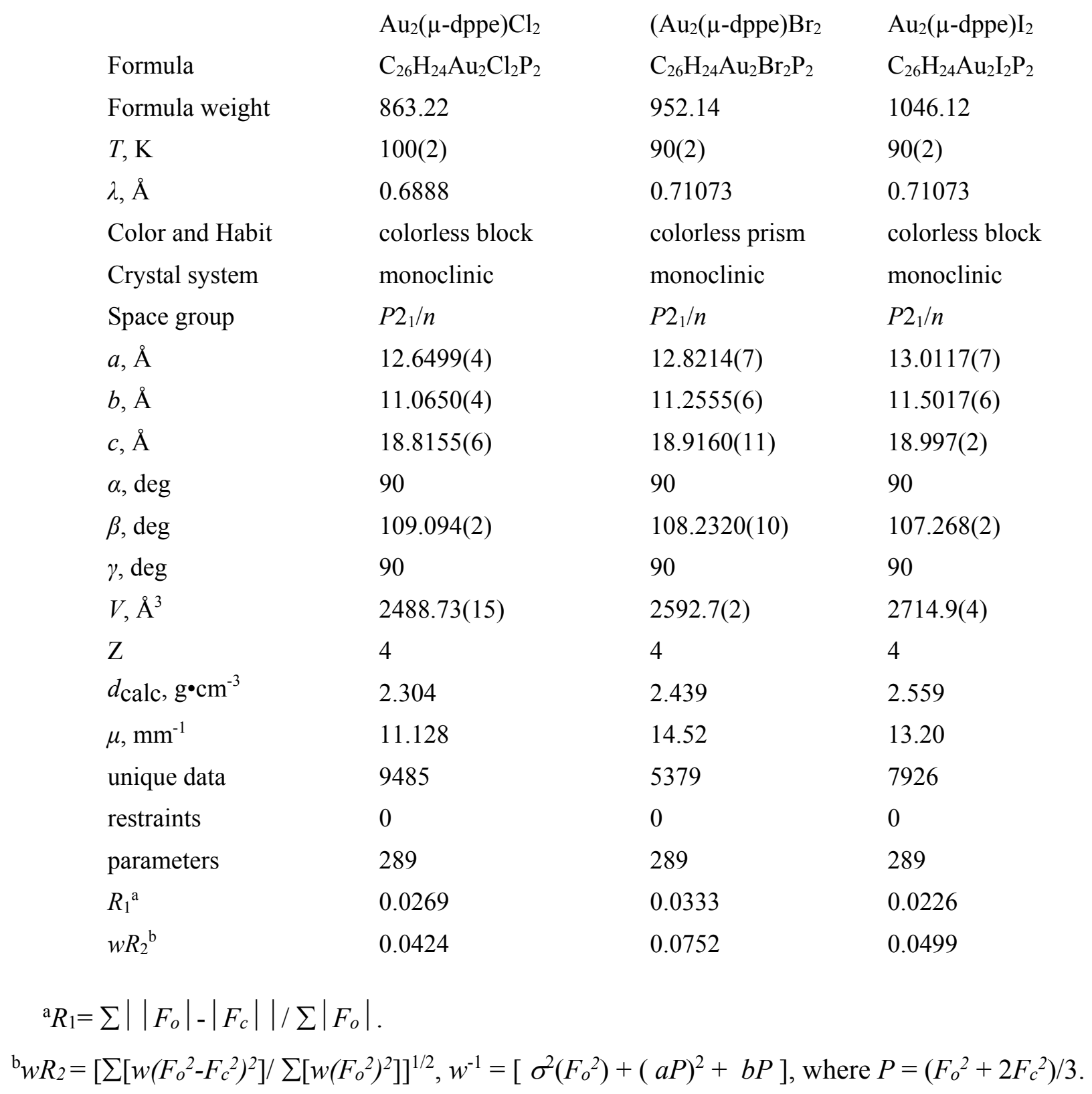


Table 2.

Selected Bond Distances $(\AA)$ and Angles (deg) for $\mathrm{Au}_{2}\left(\mu\right.$-dppe) $\mathrm{X}_{2}$

\begin{tabular}{|c|c|c|c|}
\hline & $\mathrm{Au}_{2}(\mu$-dppe $) \mathrm{Cl}_{2}$ & $\mathrm{Au}_{2}(\mu-\mathrm{dppe}) \mathrm{Br}_{2}$ & $\mathrm{Au}_{2}\left(\mu\right.$-dppe) $\mathrm{I}_{2}$ \\
\hline Distance, $\AA$ & & & \\
\hline $\begin{array}{l}\text { Au1---Au2 } \\
\text { intramolecular }\end{array}$ & $6.2299(2)$ & $6.3040(5)$ & $6.3686(4)$ \\
\hline $\begin{array}{l}\text { Au1 } \cdots \text { Au } 2 \mathrm{~A} \\
\text { intermolecular }\end{array}$ & $3.16188(17)$ & $3.1703(4)$ & $3.1552(2)$ \\
\hline Au1-P1 & $2.2309(8)$ & $2.2454(19)$ & $2.2624(9)$ \\
\hline $\mathrm{Au} 2-\mathrm{P} 2$ & $2.2333(8)$ & $2.240(2)$ & $2.2552(10)$ \\
\hline Au1-X1 & $2.2991(8)$ & $2.4242(9)$ & $2.5822(3)$ \\
\hline $\mathrm{Au} 2-\mathrm{X} 2$ & $2.3055(7)$ & $2.4263(9)$ & $2.5738(4)$ \\
\hline $\begin{array}{l}\text { X1-Au1---Au2-X } \\
\text { Newman } \\
\text { projection, deg }\end{array}$ & 61.1 & 60.9 & 58.2 \\
\hline Bond Angles, deg & & & \\
\hline P1-Au1-X1 & $172.86(3)$ & $171.74(6)$ & $169.56(2)$ \\
\hline P2-Au2-X2 & $175.27(3)$ & $175.10(5)$ & 174.17(3) \\
\hline
\end{tabular}


Table 3

Crystal Data and Structure Refinement for $\mathrm{Au}_{2}(\mu$-dcpe $) \mathrm{X}_{2}$

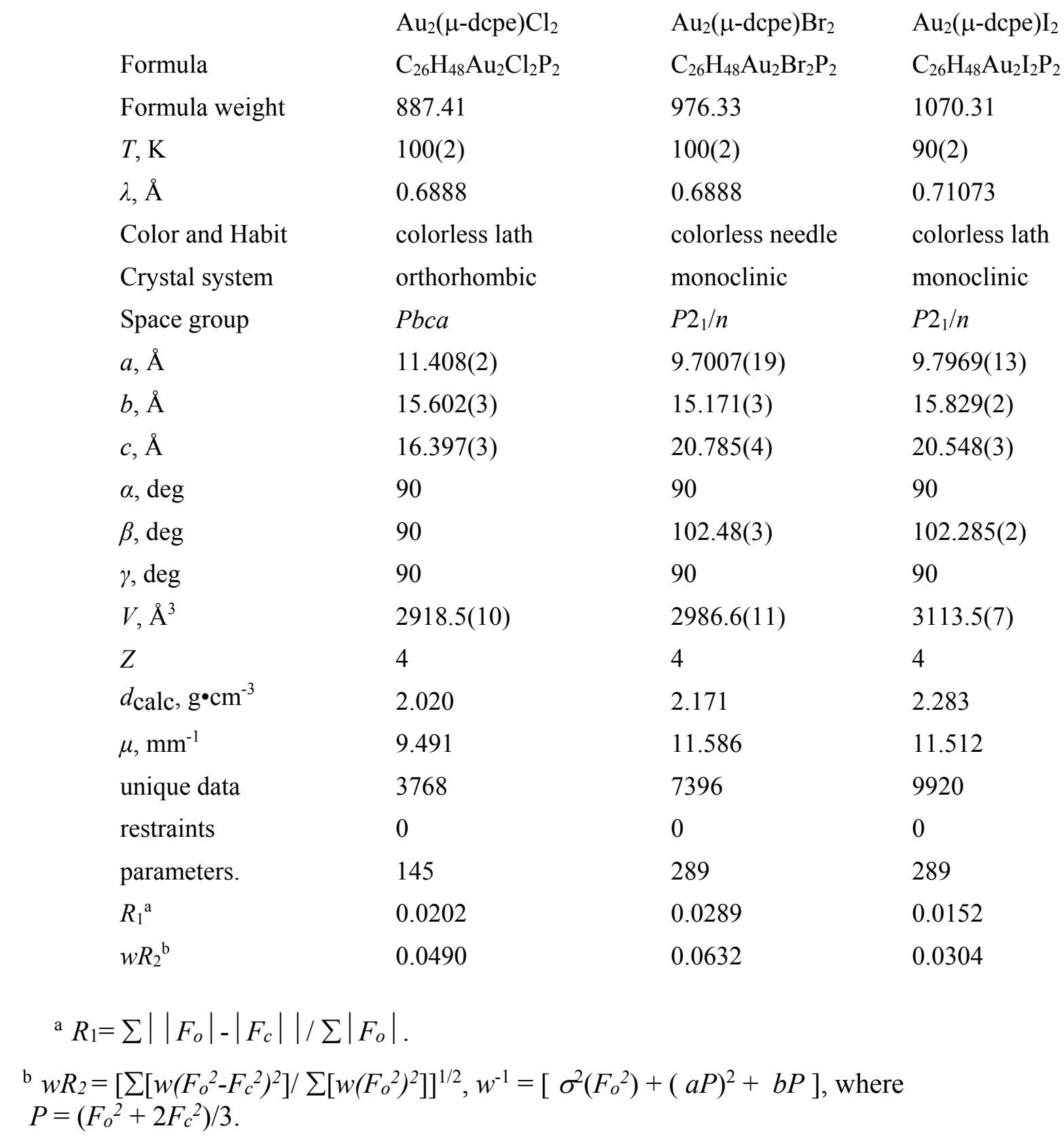


Table 4.

Selected Bond Distances $(\AA)$ and Angles (deg) for $\mathrm{Au}_{2}\left(\mu\right.$-dcpe) $\mathrm{X}_{2}$

\begin{tabular}{|c|c|c|c|}
\hline & $\mathrm{Au}_{2}(\mu$-dcpe $) \mathrm{Cl}_{2}$ & $\mathrm{Au}_{2}(\mu$-dcpe $) \mathrm{Br}_{2}$ & $\mathrm{Au}_{2}(\mu-\mathrm{dcpe}) \mathrm{I}_{2}$ \\
\hline Distance, $\AA$ & & & \\
\hline $\begin{array}{l}\text { Au1... Au2(Au1A) } \\
\text { intramolecular }\end{array}$ & $6.8374(9)$ & $3.1511(7)$ & $3.1087(4)$ \\
\hline Aul-P1 & $2.2448(9)$ & $2.2436(13)$ & $2.2607(5)$ \\
\hline $\mathrm{Au} 2-\mathrm{P} 2$ & & $2.2384(13)$ & $2.2582(5)$ \\
\hline Au1-X1 & $2.3158(8)$ & $2.4060(7)$ & $2.5672(3)$ \\
\hline Au2-X2 & & $2.4061(6)$ & $2.5708(3)$ \\
\hline $\begin{array}{l}\text { X-Au••Adu-X } \\
\text { Newman projection, } \\
\text { deg }\end{array}$ & 180 & 68.9 & 67.4 \\
\hline Bond Angles, deg & & & \\
\hline P1-Au1-X1 & $177.07(3)$ & $171.74(4)$ & $169.75(2)$ \\
\hline P2-Au2-X2 & & $174.42(4)$ & $172.95(2)$ \\
\hline
\end{tabular}


(A)

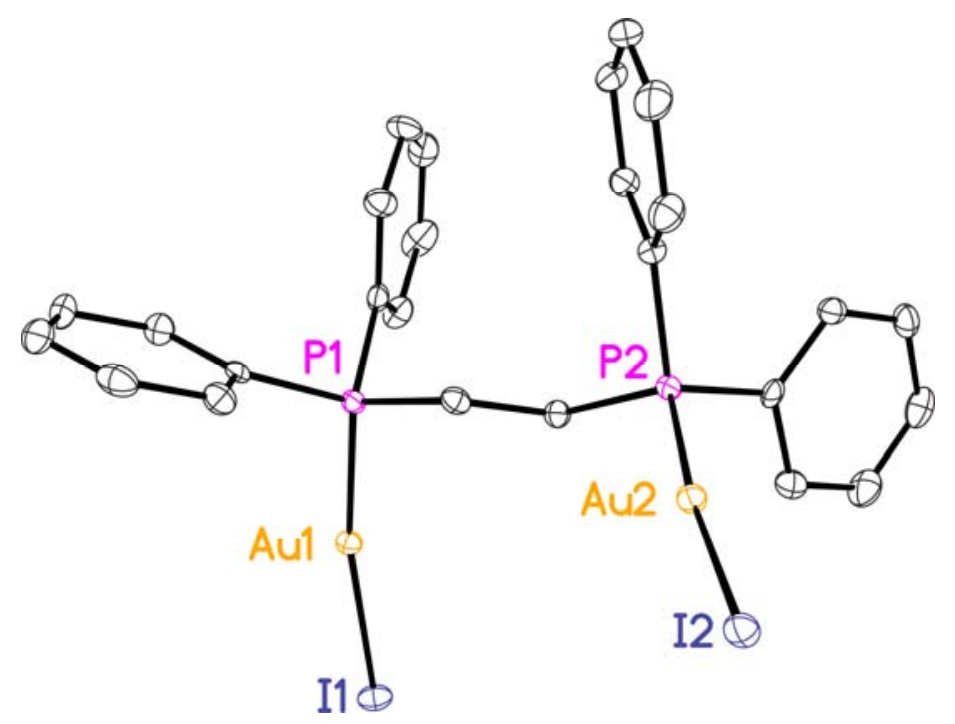

(B)

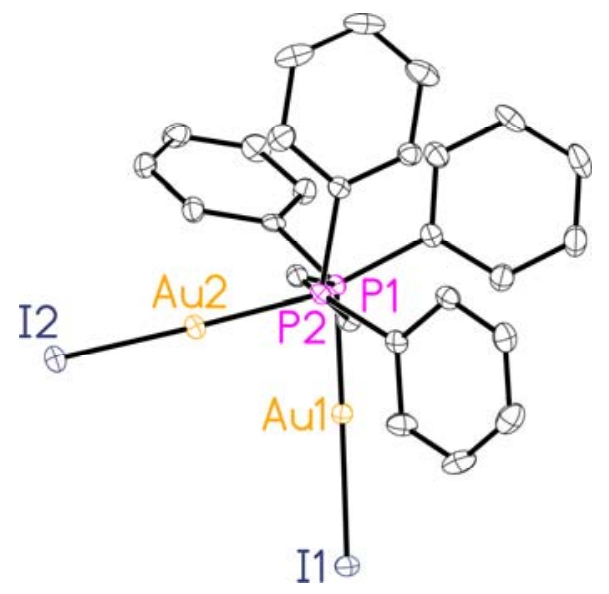

Figure 1. Two views of the structure of an individual $\mathrm{Au}_{2}\left(\mu\right.$-dppe) $\mathrm{I}_{2}$.molecule. Thermal ellipsoids are shown at the $50 \%$ probability level in this and all subsequent figures. Hydrogen atoms are omitted for clarity in all figures. 


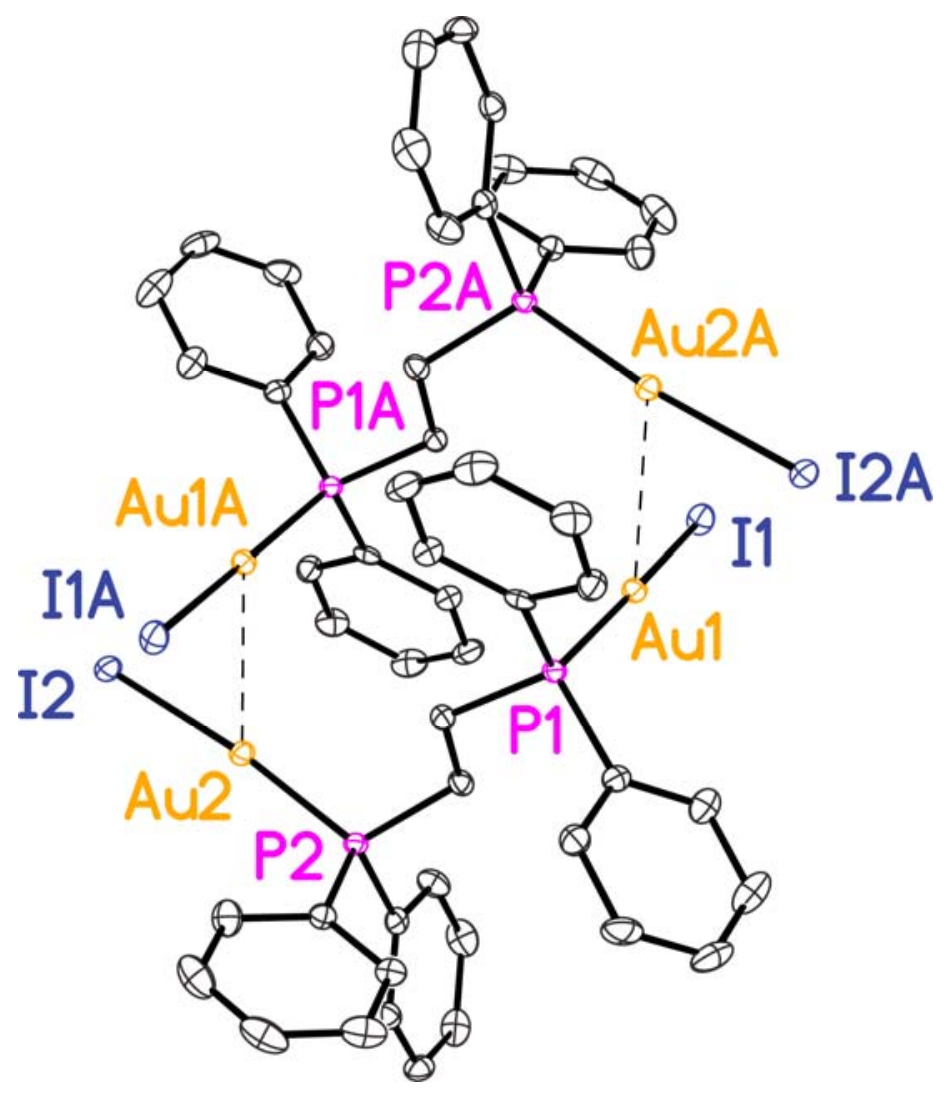

Figure 2. The interactions between two molecules of $\mathrm{Au}_{2}(\mu-\mathrm{dppe}) \mathrm{I}_{2}$.. 


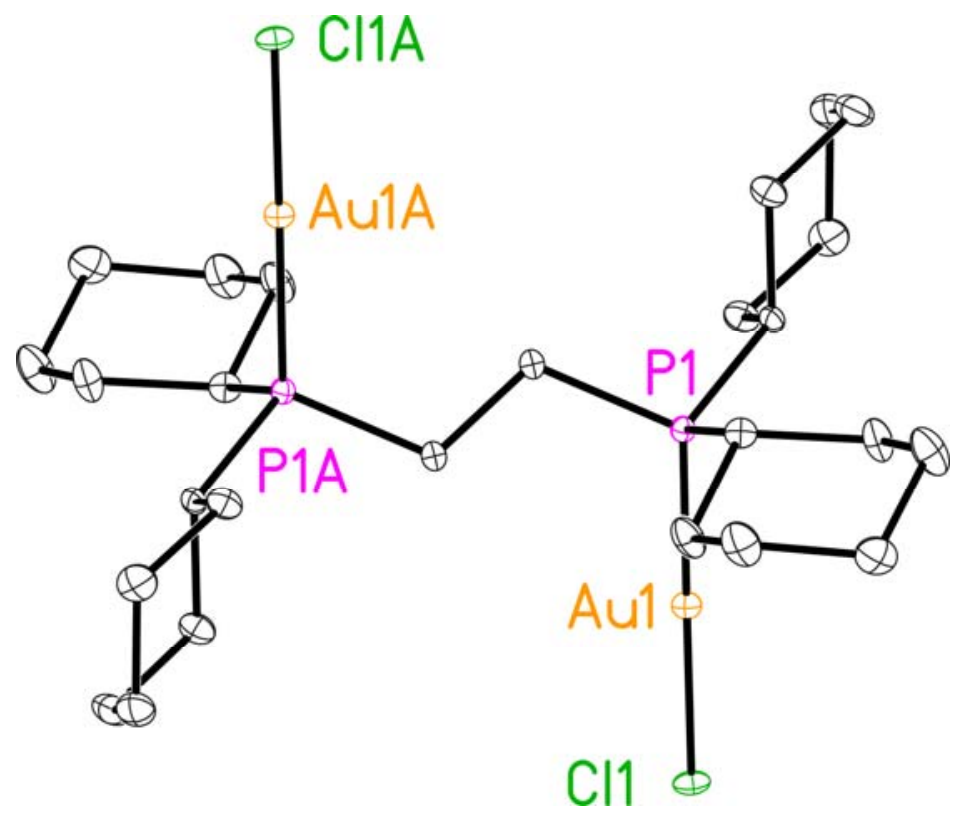

Figure 3. The structure of $\mathrm{Au}_{2}(\mu-\mathrm{dcpe}) \mathrm{Cl}_{2}$. 
(A)

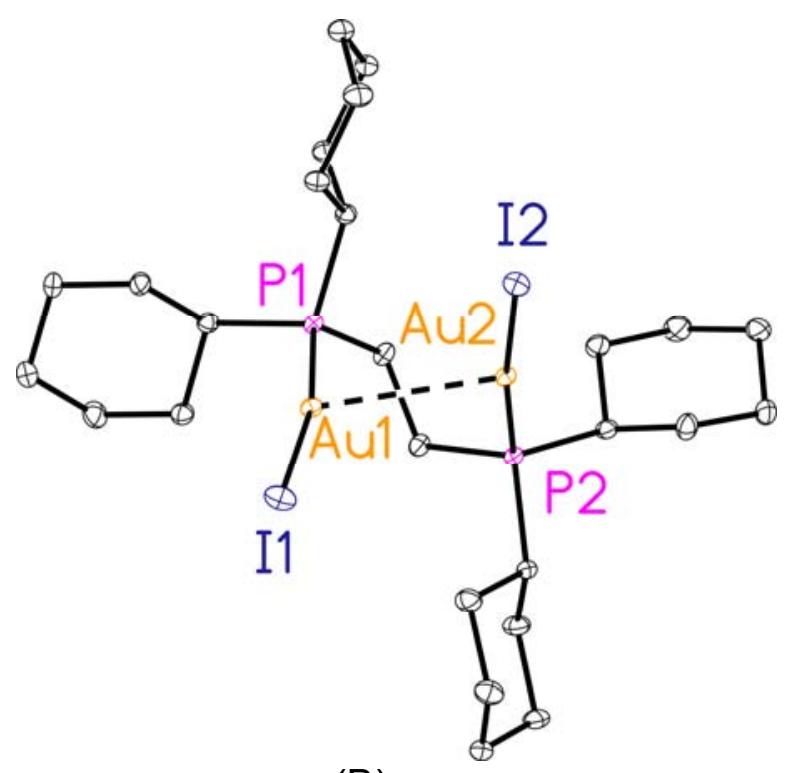

(B)

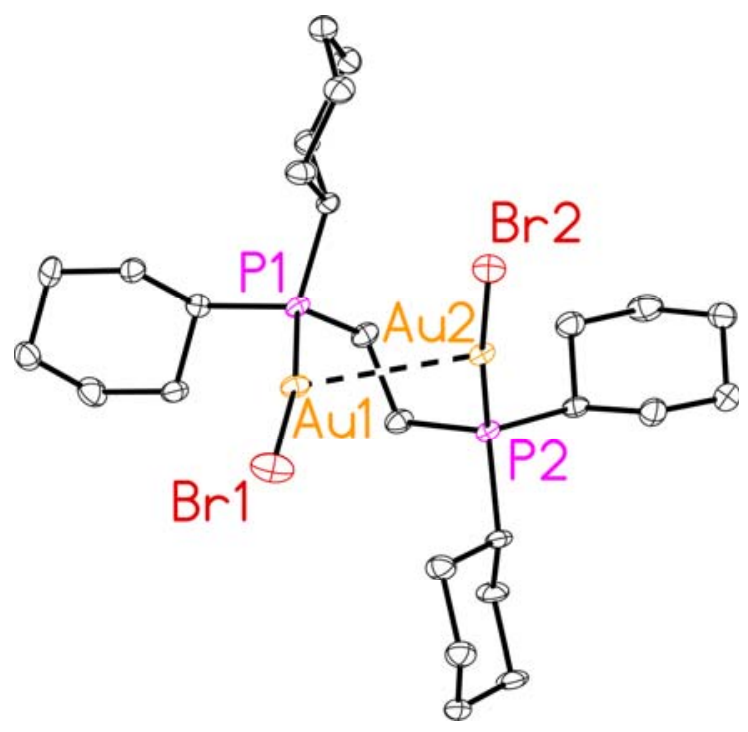

Figure 4. The structures of (A) $\mathrm{Au}_{2}(\mu$-dcpe $) \mathrm{I}_{2}$ and $(\mathbf{B}) \mathrm{Au}_{2}(\mu$-dcpe $) \mathrm{Br}_{2}$. 


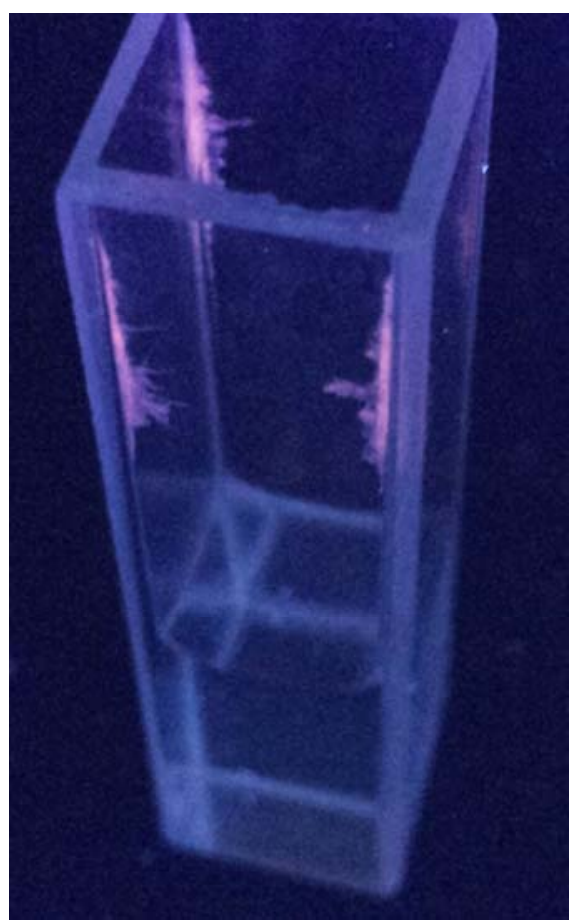

Figure 5. Luminescence from crystalline $\mathrm{Au}_{2}(\mu-\mathrm{dcpe}) \mathrm{I}_{2}$. The photograph of a cuvette containing a dichloromethane solution of $\mathrm{Au}_{2}(\mu-\mathrm{dcpe}) \mathrm{I}_{2}$ was taken under irradiation with a UV lamp. Notice that the solution is not luminescent, but that crystals of the compound, which formed by capillary action and solvent evaporation, have a pink emission. 


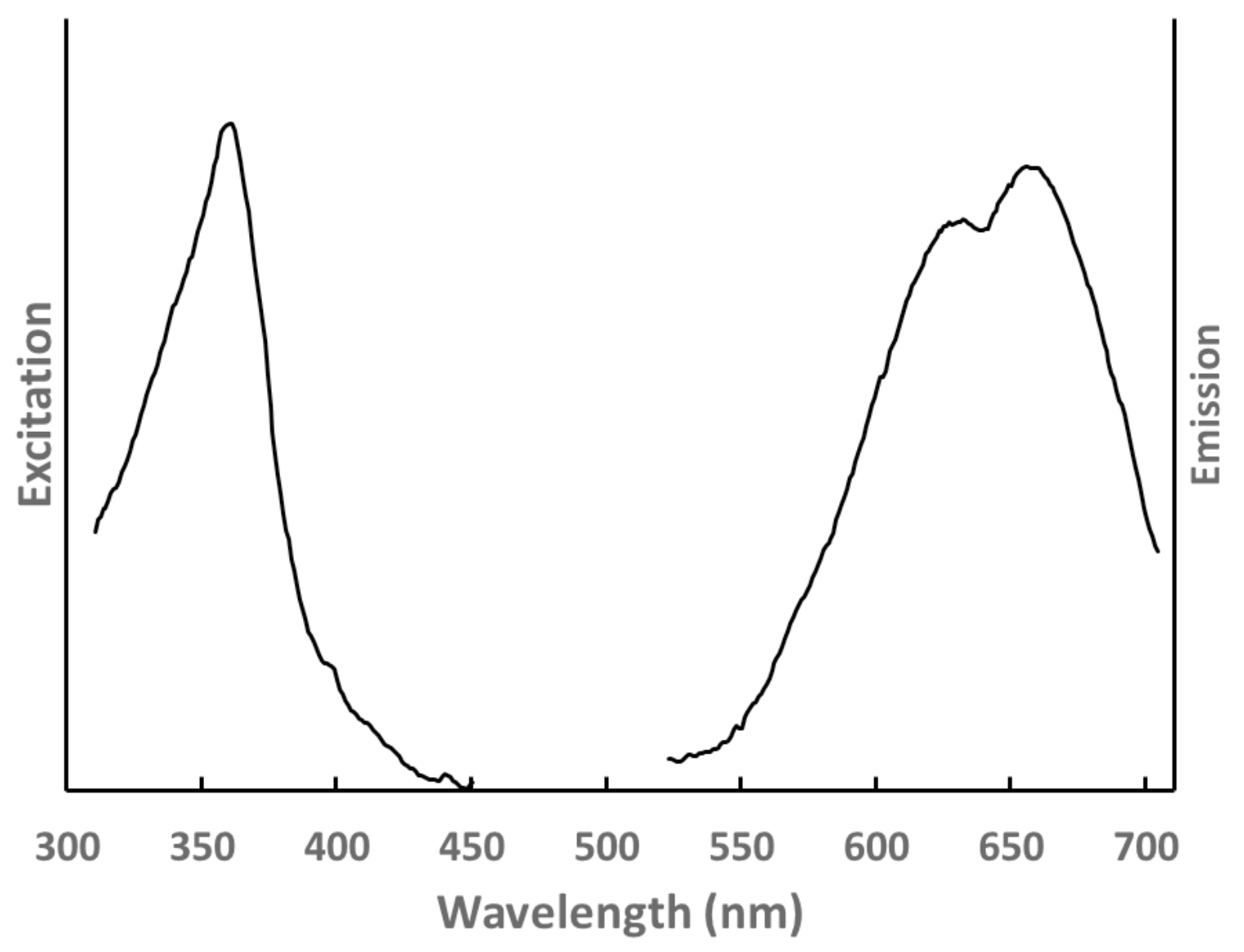

Figure 6. Emission and excitation spectra for crystalline $A_{2}(\mu$-dcpe $) I_{2}$. 


\section{Graphical Abstract.}

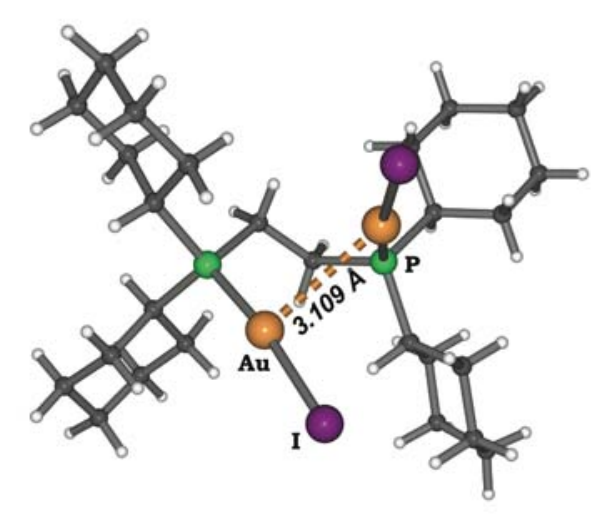

\section{Synopsis}

Aurophilic interactions in the crystal structures of the series $\mathrm{Au}_{2}(\mu-1,2-b i s($ diphenylphosphino)ethane) $\mathrm{X}_{2}$ and $\mathrm{Au}_{2}(\mu-1,2-$ bis(dicyclohexylphosphino)ethane $) \mathrm{X}_{2}(\mathrm{X}=\mathrm{Cl}, \mathrm{Br}, \mathrm{I})$ trade off with steric effects as a function of halogen atom and phenyl vs. cyclohexyl substituent. The shortest $\mathrm{Au} \cdots \mathrm{Au}$ distance of these is observed in $\mathrm{Au}_{2}(\mu-\mathrm{dcpe}) \mathrm{I}_{2}$ 